\title{
Efeito Framing: Um Estudo acerca da Variação nas Possíveis Decisões de Investimento de Estudantes de uma IES Pública na Paraíba ${ }^{1}$
}

\author{
Framing Effect: A Study about the Variation in the Possible \\ Decisions of Students Investment of a Public IES in the Paraiba
}

\section{Efecto Framing: Un Estudio sobre la Variación en las Decisiones Posibles de la Inversión de los Estudiantes de IES público en la Paraiba}

\author{
Letícia da Silva Pontes \\ Graduanda em Ciências Contábeis - UFPB \\ Endereço: Universidade Federal da Paraíba, CCSA, Campus \\ IV - PB, Alto do Cemitério \\ CEP: 58.280-000, Mamanguape, PB - Brasil, Telefone: (83) \\ 3292-3767, e-mail: josicarlass@yahoo.com.br
}

Fábio José Lira dos Santos

Professor da Universidade Federal da Paraíba e Auditor Independente, Endereço: Universidade Federal da Paraíba, CCSA, Campus IV - PB, Alto do Cemitério, CEP: 58.280-000, Mamanguape, PB - Brasil, Telefone: (83) 3292-3767, e-mail: fabioliraauditor@hotmail.com

\author{
Josicarla Soares Santiago \\ Professora Assistente da Universidade Federal da Paraíba \\ Doutoranda em Ciências Contábeis UnB \\ Endereço: Universidade Federal da Paraíba, CCSA, Campus \\ IV - PB, Alto do Cemitério \\ CEP: 58.280-000, Mamanguape, PB - Brasil, Telefone: (83) \\ 3292-3767, e-mail: josicarlass@yahoo.com.br \\ Luiz Gustavo de Sena Brandão Pessoa \\ Professor da Universidade Federal da Paraíba Endereço: \\ Universidade Federal da Paraíba, CCSA, Campus IV - PB, \\ Alto do Cemitério, CEP: 58.280-000, Mamanguape, PB - \\ Brasil, Telefone: (83) 3292-3767, e-mail: \\ gustavobrandao@bol.com.br
}

\section{RESUMO}

O estudo objetivou identificar os impactos do efeito framing nas decisões de investimento dos estudantes do curso de Ciências Contábeis e Secretariado Executivo Bilíngue da Universidade Federal da Paraíba, além de verificar possíveis diferenças na tomada de decisão destes estudantes quando expostos a situações com perspectiva de ganhos e com perspectiva de perdas. $\mathrm{O}$ estudo classifica-se como descritivo, exploratório, quali-quantitativo, com predominância qualitativa. A população do estudo é composta por aproximadamente 400 alunos, sendo a amostra composta por 210 discentes, que tiveram que escolher opções de investimentos em distintas situações. A coleta de dados deu-se através da aplicação de dois tipos de questionários, a fim de verificar se mudanças na estruturação das situações afetariam a tomada de decisão. Os resultados demonstraram que os estudantes do curso de Ciências Contábeis são conservadores, pois não se arriscaram mesmo estando em perspectivas negativas (perdas), contrariando assim a teoria dos prospectos, já os alunos de Secretariado Executivo Bilíngue mostraram-se avessos ao risco em situações com probabilidade de ganhos e propensos ao risco quando diante de situações com probabilidade de perdas. Além disso, tem-se também que as mudanças na formulação das situações não afetaram os estudantes de Ciências Contábeis e afetou em parte ( 2 das 5 situações) os discentes do curso de Secretariado Executivo Bilíngue. Pôde-se inferir que o nível de conhecimento específico e o nível de conservadorismo influenciam positivamente para o não impacto da formulação diferenciada no momento da tomada de decisão.

Palavras-chave: Informação. Finanças Comportamentais. Efeito Framing.

\section{ABSTRACT}

The study aimed to identify the impacts of the effect framing in the decisions of investment of the students of the course of Accounting and Executive Bilingual Secretariate of the Federal University of the Paraiba, besides checking possible differences in the taking decision of these students when exposed to situations with perspective of profits and with perspective of losses. The study is classified how descriptively, exploratorio, quali-quantitative, with qualitative predominance. The population of the study is composed by approximately 400 pupils, being the sample composed by 210 pupils, which they had to choose options of investments in different situations. The collection of data happened

\footnotetext{
1 Artigo recebido em 25.06.2014. Ajustado e Aceito para publicação em 11.09.2014. Recomendado para publicação por José Ribamar Marques de Carvalho (Editor Científico). Publicado em 30.12.2014. Organização responsável CCJS/UFCG.
} 
through the application of two types of questionnaires, in order to check if changes in the structuring of the situations would affect the taking decision. The results demonstrated that the students of the course of Accounting Sciences are conservative, since there were not even already risked being in negative perspectives (losses), contradicting so the Prospect theory, the pupils of Executive Bilingual Secretariate they appeared opposite to the risk in situations with probability of profits and inclined to the risk when before situations with probability of losses. Besides, it has been also that the changes in the formulation of the situations did not affect the students of Accounting Sciences and it affected in part (2 of 5 situations) the pupils of the course of Executive Bilingual Secretariate. It was possible to infer that the level of specific knowledge and the level of conservatism influence positively for not impact of the formulation differentiated in the moment of the taking decision.

Keywords: Information. Finances Comportamentais. Effect Framing.

RESUMEN

El estudio pretendió identificar los impactos del efecto Framing en las decisiones de inversión de los estudiantes del curso de Contabilidad y Secretariate ejecutivo bilingüe de la Universidad Federal del Paraiba, además de la comprobación de diferencias posibles en la decisión de estos estudiantes cuando expuesto a situaciones con la perspectiva de ganancias y con la perspectiva de pérdidas. El estudio es clasificado como descriptivo, exploratório, quali-cuantitativo, con el predominio cualitativo. La población del estudio es formada por aproximadamente 400 alumnos, siendo la muestra formada por 210 alumnos, que ellos tuvieron que elegir las opciones de inversiones en situaciones diferentes. La colección de datos pasó por la aplicación de dos tipos de cuestionarios, a fin de comprobar si los cambios de la estructuración de las situaciones afectarían la decisión de toma. Los resultados demostraron que los estudiantes del curso de Contabilidad son conservadores, ya que ni siquera se arriesgados hasta ya estando en perspectivas negativas (pérdidas), contradiciendo tan la teoría de Prospectos, los alumnos de Secretariate ejecutivo bilingüe ellos aparecieron enfrente del riesgo en situaciones con la probabilidad de ganancias y se inclinaron al riesgo cuando se enfrentam a situaciones con la probabilidad de pérdidas. Además, ha sido también que los cambios de la formulación de las situaciones no afectaron a los estudiantes de Contabilidad y esto afectó en parte (2 de 5 situaciones) a los alumnos del curso de Secretariate ejecutivo bilingüe. Era posible deducir que el nivel del conocimiento específico y el nivel de conservadurismo influyen positivamente para no el impacto de la formulación diferenciada en el momento de la decisión de toma.

Palabras claves: Información. Finanzas Comportamentais. Efecto Framing.

\section{INTRODUÇÃO}

Em todos os momentos decisões são tomadas, das mais simples, as mais complexas. O processo de escolha muitas vezes é dificultado pela escassez de informação que o sustente. Na hora de se efetuar uma escolha acerca de onde, como e quanto investir, a informação se faz ainda mais necessária, sendo importante a sua qualidade para que assim ela possa dar suporte para que o investidor identifique quais as empresas boas e quais as empresas ruins para aplicação de seu dinheiro.

O princípio da racionalidade total do homem no momento da tomada de decisão é base da Hipótese de Mercado Eficiente e um dos pilares da teoria das finanças modernas (FAMA, 1970). Com o passar dos anos essa teoria foi sendo questionada, como exemplo tem-se os trabalhos de Kahneman e Tversky (1979) e Tversky e Kahneman (1974), que passaram a estudar a figura do ser humano e suas influências pessoais na tomada de decisão. Esses estudiosos identificaram que o ser humano era extremamente influenciado pelas suas emoções e sentimentos no momento de tomar decisões, principalmente àquelas arriscadas, que fazem com que essas decisões nem sempre sejam as mais coerentes e livres de erros.

As finanças comportamentais têm sua base na teoria do prospecto que estuda o processo de tomada de decisão em situações distintas, como àqueles referentes ao efeito framing (formulação). O trabalho de Kahneman e Tversky (1984) evidencia que o ser humano toma decisões diferenciadas quando expostos a diferentes formulações de um mesmo problema. $\mathrm{O}$ efeito framing refere-se às concepções das pessoas deparadas a momentos decisórios quanto aos atos, resultados e contingências 
associadas com suas escolhas. A decisão, nessa situação, seria controlada parcialmente pela estrutura do problema e pelas características pessoais do decisor.

Diante disso, o presente estudo busca respostas para o seguinte questionamento: “Quais os impactos do efeito framing nas decisões dos estudantes dos cursos de Ciências Contábeis e Secretariado Executivo Bilíngue de uma IES pública na Paraíba?"

Visando atingir respostas ao questionamento proposto tem-se como objetivo geral: Identificar os impactos do efeito framing nas decisões de investimento dos estudantes dos cursos de Ciências Contábeis e Secretariado Executivo Bilíngue de uma IES pública na Paraíba. Assim como os objetivos específicos: Analisar se há diferença nas decisões tomadas pelos estudantes do curso de Ciências Contábeis e Secretariado Executivo Bilíngue da IES estudada; e verificar os principais fatores que influenciam a tomada de decisão dos estudantes do curso de Ciências Contábeis e Secretariado Executivo Bilíngue.

O trabalho se justifica pela importância do estudo da tomada de decisão de possíveis investidores e dos impactos que seus aspectos emocionais e psicológicos causam nessas decisões, contribuindo assim para a melhor compreensão de suas falhas cognitivas, evitando possíveis perdas ocasionadas por escolhas enviesadas. Embasando essa ideia da importância do estudo do investidor e suas emoções no momento de tomada de decisão, Tomaselli (2010, p. 538) diz que "quando um investidor consegue olhar para si, de modo a entender e a aceitar suas emoções autênticas, seu processo de tomada de decisão ocorrerá com mais facilidade e assertividade".

Ao considerar que entender o comportamento do investidor, torna-se um ponto que requer cada vez mais atenção, considerando que se tomou destaque o aumento da participação de investidores pessoa física no mercado de capitais brasileiro, visto que em maio de 2013 o número de investidores individuais na Bovespa bateu recorde chegando a um número de contas registradas de 637.198, sendo o recorde anterior de 630.895, registrado em setembro de 2010 (YAZBEK, 2013).

\section{FUNDAMENTAÇÃO TEÓRICA}

\subsection{AS FINANÇAS COMPORTAMENTAIS E O EFEITO FRAMING}

As finanças comportamentais surgiram em contraposição a Hipótese de Mercado Eficiente (HME). A HME defende a racionalidade do investidor, considerando que o mesmo tem ao seu dispor todas as informações necessárias para sua tomada de decisão (FAMA, 1970). 
No entanto, apesar da grande contribuição para a teoria das finanças a HME recebeu diversas críticas. A teoria da racionalidade ilimitada do indivíduo foi motivo de contestação por autores como os psicólogos Kahneman e Tversky em seus principais estudos nos anos de 1974 e 1979 que mostram que o indivíduo usa de elementos de natureza humana quando deparado com incerteza e condições de risco, fazendo com que surgissem as finanças comportamentais.

Assim, sugiram afirmativas que os investidores não são totalmente racionais em suas tomadas de decisão, pois esses processos eram fortemente impactados por aspectos psicológicos. Essa ideia é fortalecida por Carmo (2005) que afirma que as finanças comportamentais surgem com o intuito de contestar a racionalidade ilimitada, incluindo a psicologia e sociologia aos modelos clássicos, com o objetivo de entender melhor a tomada de decisão no ambiente das finanças.

Contribuindo com isso, Kimura (2003, p. 3) esclarece que:

As finanças comportamentais representam um novo ramo na teoria financeira, que busca incorporar os aspectos psicológicos dos indivíduos no processo de avaliação e precificação de ativos financeiros.

Os alicerces das finanças comportamentais encontram-se centrados nos trabalhos de dois psicólogos e docentes israelenses: Amós Tversky e Daniel Kahneman. Os trabalhos destes, entre os anos de 1974 e 1979, representam a base teórica para a análise do comportamento de investidores e foram fundamentais para o desenvolvimento das finanças comportamentais.

Tversky e Kahneman (1974) apresentaram três heurísticas em seu trabalho Judgment under uncertainty: heuristics and biases, são elas a heurística da representatividade, a disponibilidade e a ancoragem.

Milanez (2003, p. 20) diz que:

As regras de bolso (heuristics) são o meio pelo qual os agentes encontram soluções ótimas, levando em consideração os custos para tomar decisões plenamente racionais, uma vez que é da natureza humana a presença de limitações ao exercício da plena e ilimitada racionalidade.

“No caso de investimentos, a heurística da representatividade pode influenciar a percepção dos investidores sobre o potencial de valorização de uma ação." (KIMURA, 2003, p. 4). Considerando que usa a intuição a partir de determinados comportamentos padrões no sentido da realização de previsões.

A heurística da disponibilidade ocorre porque os indivíduos tendem a concentrar sua atenção em um acontecimento particular em vez do acontecimento completo, somente porque este fato esta mais presente em sua mente (TVERSKY; KAHNEMAN, 1974).

A ancoragem ocorre quando as pessoas fazem estimativas de determinadas probabilidades a partir de um ponto inicial, que pode ser sugerido pela estruturação do problema (TVERSKY; KAHNEMAN, 1974). 
Outro trabalho de Kahneman e Tversky de extrema importância para as finanças comportamentais é a Teoria dos Prospectos (Prospect Theory: an analysis of decision under risk) de 1979 que vai contra a Teoria da Utilidade Esperada (TUE) que afirma que os indivíduos são avessos ao risco em qualquer situação, são totalmente racionais e buscam a maximização da utilidade (HAUBERT; LIMA; HERLING, 2012).

Para Lima (2003, p. 10) “a 'Prospect Theory' pode ser representada de diversas maneiras, mas em essência, ela descreve diferentes estados mentais que podem ser influenciadores no processo de tomada de decisão".

$\mathrm{Na}$ teoria dos prospectos a aversão ao risco apenas ocorre quando se fala de ganhos, porém, quando se apresenta a possibilidade de perda para o indivíduo, o mesmo tende a se arriscar. Isso se dá ao fato de que a sensação associada à perda é bem maior que a sensação prazerosa ligada ao ganho do mesmo valor (KAHNEMAN; TVERSKY, 1979).

Segundo esses autores uma escolha entre expectativas de riscos apresenta diversos efeitos intensos que não consistem com os preceitos básicos da TUE. Esses efeitos fazem com que os investidores avaliem parcialmente perspectivas futuras que envolvem risco e incerteza. Kahneman e Tversky destacam nesse trabalho três efeitos. São eles: o efeito certeza, o efeito reflexão e o efeito isolamento.

Galeno et al (2009, p. 5) afirma que “o efeito certeza está relacionado à superestimação de resultados considerados certos pelos entrevistados".

Acerca do efeito reflexão, Torralvo (2010, p. 25) afirma "que o efeito reflexão implica aversão a risco, quando a perspectiva é positiva, e busca por risco, quando a perspectiva é negativa".

O terceiro é o efeito isolamento que está relacionado ao descarte, por parte dos respondentes, de informações semelhantes entre alternativas, focando assim apenas em fatores diferentes (GALENO et al., 2009). E esse isolamento de informações no momento da tomada de decisão faz surgir o efeito framing.

O efeito framing ou formulação foi desenvolvido na Teoria dos Prospectos de Kahneman e Tversky (1979) e compreende a existência de respostas diferentes por parte das pessoas a um mesmo problema decisório devido a alterações na forma de apresentação do problema.

Segundo Mayer e Avila (2010), o efeito framing é a probabilidade de influenciar a decisão de um indivíduo apresentando as informações de modo verídico, sem distorções, apenas com mudanças sutis em sua estruturação num mesmo problema.

Kahneman e Tversky (1984) identificaram duas fases no processo de tomada de decisão em situação de risco: a fase da análise do problema e a fase da avaliação. Para Torralvo (2010, p. 28) "na primeira etapa, é realizada uma análise preliminar das perspectivas oferecidas, resultando numa simplificação dessas perspectivas". Ferreira Jr. (2012, p. 64) explica que a fase de avaliação é aquela "em que se mensura os resultados que poderão ser obtidos para cada uma das alternativas possíveis, sendo que aquela que apresentar maior resultado tende a ser a escolhida". 
Ferreira Jr. (2012, p. 64) ainda afirma que "a forma como o indivíduo percebe e analisa o problema é influenciada por diversas variáveis ambientais como hábitos do indivíduo e da sociedade como um todo, o código de ética estabelecido, as normas e leis, as expectativas e aspirações pessoais do indivíduo, entre outros".

Contudo, Kahneman e Tversky (1979) destacam que existe uma tendência de que as pessoas têm mais aversão ao risco do que ao ganho, preferindo um ganho pequeno, mas certo, do que maior ganho com probabilidade de não o alcançar. Assim com seus experimentos se foi possível comprovar que os indivíduos mudam de um estado de aversão ao risco para um comportamento de propensão ao mesmo quando uma situação é apresentada em perspectivas distintas (positiva ou negativa).

Kahneman e Tversky (1984) alertam que o efeito framing pode acontecer por acaso, sem que ninguém perceba o impacto da formulação do problema sobre a decisão final, mas também pode ser explorado deliberadamente a fim de moldar a atratividade das opções, sendo esse efeito usado na tentativa de influência no mercado de capitais.

\section{PROCEDIMENTOS METODOLÓGICOS}

A pesquisa caracterizou-se quanto à natureza dos objetivos como um estudo descritivo, sendo ainda caracterizada como exploratória. Em relação à abordagem do problema, a pesquisa é caracterizada como quali-quantitativa, com predominância qualitativa.

A coleta de dados deu-se através de aplicação de questionários com alunos dos cursos de Ciências Contábeis e Secretariado Executivo Bilíngue da Universidade Federal da Paraíba no campus IV Litoral Norte - Mamanguape para averiguar o perfil de tomada de decisão sobre investimentos, considerando esses acadêmicos como propensos investidores. O curso de Secretariado foi escolhido para comparação dos resultados com o Curso de Ciências Contábeis por também ser uma ciência social e abordar em sua grade curricular disciplina ligada à contabilidade, como é o caso da disciplina de Gestão Contábil para Secretariado.

Foram estruturados dois questionários, com situações em ambiente de ganhos e perdas e com uma formulação diferenciada. A sua aplicação se deu com os alunos de graduação a partir do $5^{\underline{0}}$ período para o curso de Ciências Contábeis e a partir do $4^{\circ}$ período para o curso de Secretariado Executivo Bilíngue. Incluindo-se então os dois cursos, contou-se com uma população equivalente a cerca de 400 estudantes, sendo a amostra composta por 210 estudantes, 100 alunos do curso de Ciências Contábeis e 110 do curso de Secretariado Executivo Bilíngue, entre os meses de maio e junho de 2014. Do total da amostra, 96 discentes responderam o questionário tipo 1 e 114 o questionário tipo 2.

A amostragem é a não-probabilística, caracterizada como sendo por conveniência do autor. Esses questionários foram aplicados em salas de aula, sendo de forma aleatória a escolha de que sala de aula foi aplicado cada tipo de questionário. 
Para revisão da literatura foi realizado um levantamento bibliográfico que tomou como base principal artigos, teses, dissertações nacionais e internacionais sobre o tema.

Os dados obtidos foram analisados através da ferramenta estatística Excel 2010 da Microsoft. Nessa ferramenta os dados foram tabulados e analisados, assim como montados todos os gráficos para evidenciação dos resultados.

\section{APRESENTAÇÃO E ANÁLISE DOS RESULTADOS}

Identificando a amostra estudada verificou-se que o estudo contou com a participação de 210 alunos, onde 100 alunos (47,6\%) são do curso de Ciências Contábeis e 110 alunos (52,4\%) são do curso de Secretariado Executivo Bilíngue.

As primeiras questões dos questionários foram constituídas por opções de investimentos em que se tem ganho certo ou probabilidade de ganho (perspectiva positiva), no questionário tipo 1 que objetivou com isso conhecer se a amostra é avessa ao risco optando por ganho certo; e com opções de investimentos onde tem-se probabilidade de perda ou perda certa (perspectiva negativa), no questionário do tipo 2, com o objetivo de conhecer se a amostra se arriscaria quando diante de situações no âmbito negativo.

Segundo a teoria dos prospectos de Kahneman e Tversky (1979) a escolha por ganhos/perdas certas indica uma aversão a perda e isso apenas ocorre quando se fala de ganhos e a escolha mais arriscada, com probabilidades de ganhos/perdas maiores indica uma propensão ao risco, coisa que ocorre apenas quando se trata de perda.

O resultado dessas opções é apresentado na tabela 1:

Tabela 1 - Alternativas de investimentos (perspectiva positiva e negativa)

\begin{tabular}{|c|c|c|c|c|c|}
\hline & \multirow{2}{*}{ Questões } & \multicolumn{2}{|c|}{ Ciências Contábeis } & \multicolumn{2}{|c|}{$\begin{array}{c}\text { Secretariado Executivo } \\
\text { Bilíngue }\end{array}$} \\
\hline & & $\begin{array}{c}\text { Tipo } 1 \\
\text { (Ganhos) }\end{array}$ & $\begin{array}{c}\text { Tipo } 2 \\
\text { (Perdas) }\end{array}$ & $\begin{array}{c}\text { Tipo } 1 \\
\text { (Ganhos) }\end{array}$ & $\begin{array}{l}\text { Tipo } 2 \\
\text { (Perdas) }\end{array}$ \\
\hline 1 & $\begin{array}{l}\text { A:(R\$2.000:100\%) } \\
\text { B:(R\$3.200:75\%; R\$0: 25\%) }\end{array}$ & $\begin{array}{l}63 \% \\
37 \%\end{array}$ & $\begin{array}{l}52 \% \\
48 \% \\
\end{array}$ & $\begin{array}{l}73 \% \\
27 \% \\
\end{array}$ & $\begin{array}{l}44 \% \\
56 \% \\
\end{array}$ \\
\hline 2 & $\begin{array}{l}\text { A:(R\$2.500:100\%) } \\
\text { B:(R\$3.200:80\%; R\$0:20\%) }\end{array}$ & $\begin{array}{l}45 \% \\
55 \% \\
\end{array}$ & $\begin{array}{l}74 \% \\
26 \% \\
\end{array}$ & $\begin{array}{l}67 \% \\
33 \% \\
\end{array}$ & $\begin{array}{l}54 \% \\
46 \% \\
\end{array}$ \\
\hline 3 & $\begin{array}{l}\text { A:(R\$1.000:100\%) } \\
\text { B:(R\$2.200:35\%; R\$0:65\%) } \\
\text { C:(R\$1.600:65\%; R\$0:35\%) }\end{array}$ & $\begin{array}{l}71 \% \\
5 \% \\
24 \% \\
\end{array}$ & $\begin{array}{c}46 \% \\
50 \% \\
4 \% \\
\end{array}$ & $\begin{array}{l}69 \% \\
15 \% \\
16 \% \\
\end{array}$ & $\begin{array}{l}31 \% \\
47 \% \\
22 \% \\
\end{array}$ \\
\hline 4 & $\begin{array}{l}A:(R \$ 5.000: 85 \%) \\
B:(R \$ 6.700: 65 \%) \\
C:(\operatorname{R} \$ 4.000: 100 \%)\end{array}$ & $\begin{array}{c}24 \% \\
8 \% \\
68 \% \\
\end{array}$ & $\begin{array}{l}18 \% \\
26 \% \\
56 \%\end{array}$ & $\begin{array}{l}20 \% \\
11 \% \\
69 \%\end{array}$ & $\begin{array}{l}14 \% \\
44 \% \\
42 \%\end{array}$ \\
\hline
\end{tabular}

Fonte: Produção do Próprio Autor.

Através da análise das informações descritas na Tabela 1, observou-se que para os alunos do curso de Ciências Contábeis a teoria dos prospectos defendida por Kahneman e Tversky (1979) não se confirma, pois os mesmos se mostraram avessos 
ao risco no campo dos ganhos e no campo das perdas, a maioria optou por um ganho certo no questionário tipo 1 e por uma perda certa no questionário tipo 2.Pode-se inferir que este resultado seja uma consequência dos princípios trabalhados no próprio curso, onde o conservadorismo é tido como um comportamento necessário ao processo de tomada de decisão, antecipando o reconhecimento das perdas e nunca antecipando os ganhos prováveis, por exigir que tais informações de ganho sejam mais verificáveis antes de reconhecê-lo (BASU, 1997). Esse fato é confirmado no trabalho de Ferreira Jr (2012) que teve como objetivo explicar os fatores e variáveis que afetam o processo de tomada de decisão dos contadores, a fim de identificar se o conservadorismo é intrínseco ao ser humano ou é característica apenas de contadores; e que concluiu, de forma geral, que os contadores tendem a serem mais conservadores do que os profissionais de outras áreas em situações de perda.

Em se tratando dos resultados obtidos com os estudantes do curso de Secretariado Executivo Bilíngue (ver tabela 2), a teoria defendida por Kahneman e Tversky (1979) se confirmou, pois eles mostraram-se avessos ao risco escolhendo as opções com ganho certo quando estavam na perspectiva positiva e propensos ao risco quando diante de perspectiva negativa, escolhendo as opções com probabilidade de maiores ganhos, que por consequência são as mais arriscadas. Isso pode ter ocorrido por fatos diversos, pode ter sido propiciado pelo perfil dos participantes, pois quando questionados sobre a profissão, foi verificado que 50 alunos (45\%) são apenas estudantes, e os demais (55\%) trabalham e estudam, isto pode afetar na percepção de aplicação de recursos, na percepção de risco, entre outras coisas. Em indagação sobre a realização de investimentos, por exemplo, se verificou $11 \%$ dos respondentes já efetuaram e/ou efetuam algum tipo de investimento. Sem contar que o tipo de investimento mais especificado foi a realização de poupança $(67 \%)$, demonstrando a opção por um título livre de risco, corroborando com a aversão ao risco. Os outros dois mais citados, compra de terrenos $(8 \%)$ e imóveis $(8 \%)$, teve participação menor, o quais poderiam ser considerados mais arriscados.

E como explica Ferreira Jr (2012), a maneira de perceber um problema e analisá-lo é influenciada por diversas variáveis, como os hábitos de um indivíduo, as influências da sociedade sobre o mesmo, as normas e leis, os desejos e expectativas pessoais, entre outros. Associado a isso, como tentativa de explicar a ocorrência desse efeito, Kahneman e Tversky (1979) afirmam que isso se dá ao fato de que a sensação associada à perda é bem maior que a sensação prazerosa ligada ao ganho do mesmo valor. O resultado obtido com os estudantes do curso de Secretariado é semelhante ao obtido nos trabalhos de Galeno et al (2009) que objetivou verificar a existência de diferenças comportamentais entre estudantes de MBA na área financeira e estudantes de MBA em administração geral diante de alternativas de investimento e no trabalho de Haubert, Lima e Herling (2012) com estudantes de pós-graduação stricto sensu com objetivo de compreender o comportamento da sua amostra, com base nas finanças comportamentais, quanto à sua atuação em investimentos. Esses autores 
verificaram que, assim como nesse caso, suas amostras apresentaram aversão ao risco em prospecto positivo e propensão ao risco quando diante de prospecto negativo.

Tversky e Kahneman (1986) explicam que a variação de descrever as alternativas em termos de ganhos e perdas com relação ao status quo (situação inicial) exerce um efeito notável na preferência dos indivíduos, pois para os mesmos uma situação apresentada ou estruturada de maneira distinta pode provocar preferências diferentes. Essa variância originou o efeito isolamento, que está relacionado ao descarte, por parte dos respondentes, de informações semelhantes entre alternativas, focando assim apenas em fatores diferentes e que tem como consequência importante o efeito framing ou efeito formulação (KAHNEMAN e TVERSKY, 1979). Assim tevese como propósito nas questões sobre o efeito framing verificar se os respondentes que se mostraram avessas ao risco seriam mais prudentes analisando com detalhe as opções e não alterando sua decisão independentemente das mudanças na formulação, não sendo afetado pelo efeito isolamento.

Tratando-se das questões que buscaram verificar a existência do efeito framing, foram estruturadas cinco questões que tomaram por base o trabalho de Silva e Lima (2007) realizado com discentes dos cursos de Administração e Ciências Contábeis de instituições públicas e particulares de Brasília, João Pessoa e Natal e o trabalho de Lima (2012), realizado com professores e alunos do curso de Administração e Ciências Contábeis e profissionais de mercado dessas áreas.

O quinto problema do questionário aplicado apresentava relatórios de duas empresas, um com informações diretas sobre a receita e lucro anual, outro com informações mais detalhadas que evidenciavam o valor de mercado da empresa juntamente com receita e lucro. A formulação realizada entre os tipos de questionários, foi a troca das informações entre as empresas A e B, nos questionário tipo 1 a empresa A foi a que apresentou seu resultado de forma direta e apresentava menor lucro e a empresa B a que apresentou seu resultado de forma mais detalhada, com lucro maior que o da empresa $\mathrm{A}$, e nos questionários tipo 2 a empresa $\mathrm{A}$ foi a que apresentou seu resultado de forma mais detalhada e apresentava menor lucro e a empresa B apresentou seu resultado de forma direta com lucro maior que o da empresa A. O objetivo dessa mudança era saber se os estudantes optariam em investir seu capital apenas em empresas com lucros elevados, associado ou não a um bom nível de informação. O resultado obtido foi o exposto no gráfico 1.

Gráfico 1: Informação simplificada X informação mais detalhadas 


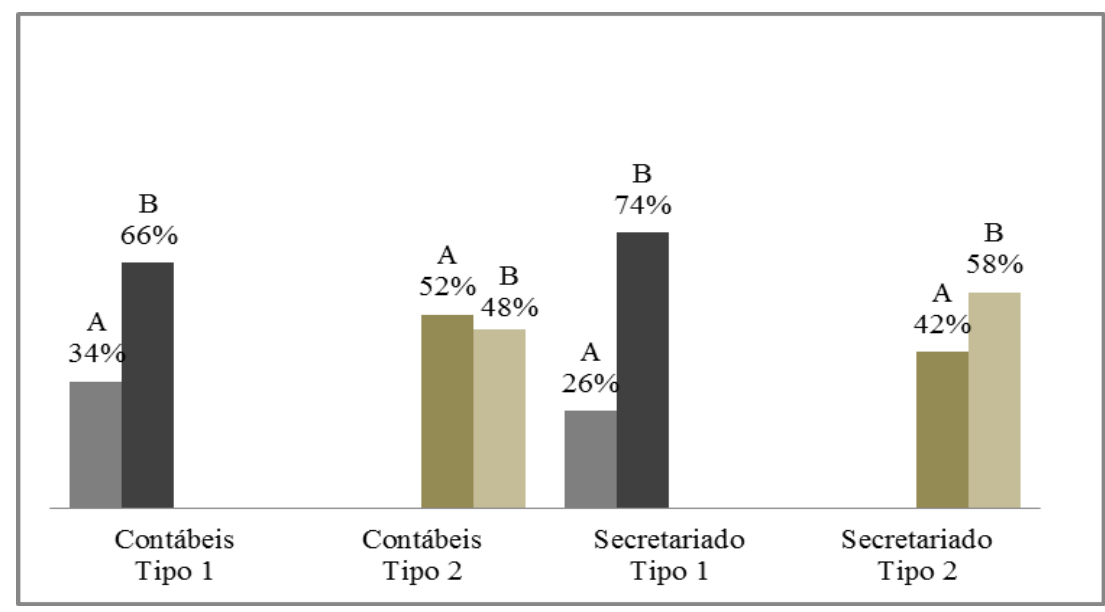

Fonte: Produção do Próprio Autor.

Através da análise do gráfico, observou-se que nesse problema a maioria dos alunos do curso de Ciências Contábeis investiram seu capital na empresa que forneceu mais informações, assim pode-se afirmar que os discentes do curso de Ciências Contábeis preferem efetuar suas escolhas em cima de informações sobre o valor de mercado das empresas, que traz consigo informações determinantes que evidenciam as perspectivas da empresa, fato importante para um investidor que espera lucros por diversos períodos. Referindo-se aos alunos do curso de Secretariado Executivo Bilíngue, tem-se exatamente o contrário. Essa amostra revelou-se mais vulneráveis aos efeitos ocasionados pelo framing, confirmando a teoria defendida por Kahneman e Tversky (1984), sobre o fato de existir diferentes escolhas ocasionadas por mudanças na forma de apresentação dos resultados. Para os alunos de Secretariado, em sua maioria, o importante foi o lucro da empresa e assim quanto isso lhes trariam de retorno, esquecendo o valor da informação e deste modo, sua importância em decisões presentes com impactos futuros.

O sexto problema do questionário aplicado tinha o objetivo de verificar se a tomada de decisão é impactada por formas distintas de apresentar o resultado. Assim foi estruturado, no tipo de questionário 1, um demonstrativo contábil evidenciando a formação do lucro daquela empresa, e no tipo de questionário 2, esses mesmos resultados foram evidenciados em forma de texto, com o uso da porcentagem para mostrar as variações ocorridas, e ao fim perguntado se efetuaria um investimento de capital naquela empresa, depois da análise do exposto. A intenção de se realizar essa pergunta foi buscar saber se a evidenciação com porcentagens impactaria de forma negativa o tomador de decisão, pois ao analisar demonstrativos, muitas vezes, não atenta-se a quanto cada despesa/custo representa da receita, fixando-se assim apenas na receita e no lucro, sendo esquecido os demais itens que impactam o mesmo e o texto informativo dessa pergunta focou principalmente nesse ponto. 


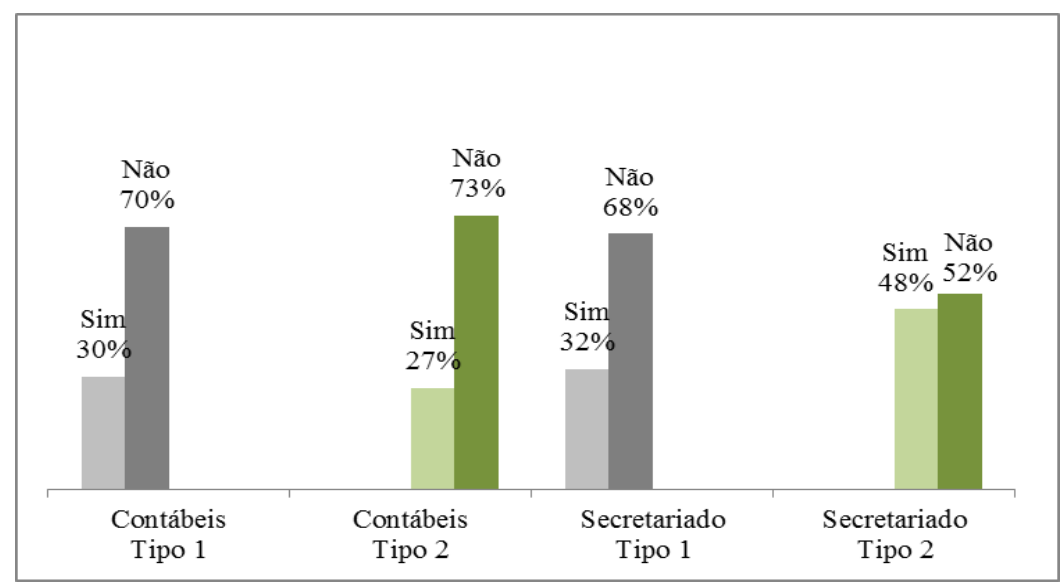

Fonte: Produção do Próprio Autor.

Nesse problema tanto os alunos de Ciências Contábeis, quanto de Secretariado Executivo Bilíngue, não foram afetados pelo efeito formulação a que foram expostos, mostrando assim o não impacto em suas decisões quando expostos a formas distintas de evidenciar uma informação. Acredita-se que os respondentes analisaram detalhadamente toda a formação do lucro da empresa, podendo esse ser um fator significativo para que se alcançasse esse resultado. Essa preocupação em analisar a formação o lucro pode ser consequência do aprendizado obtido dentro da universidade com disciplinas como as de práticas contábeis (Contabilidade I, II, III e IV) e Análise das Demonstrações Contábeis para os estudantes de contabilidade e a disciplina de Gestão Contábil para o curso de Secretariado.

No sétimo problema do questionário aplicado, buscou-se algo semelhante ao problema anterior, saber se a evidenciação com porcentagens impactaria de forma negativa o tomador de decisão, tendo de diferente daquela, o ponto de partida da questão, pois os respondentes tinham que considerar-se um investidor, e não mais como um possível investidor daquela empresa, assim esse problema partia de um segundo estágio; além disso eles tinham que realizar análises da condição atual e futura da empresa. Como dito, nesse problema os respondentes teriam que imaginar que já tinham aplicado um capital nessa empresa e com o passar do tempo a diretoria propôs um investimento em busca de diferencial competitivo, apresentando assim como seria o resultado da empresa depois dessa aplicação. A formatação do problema também se deu de forma semelhante ao problema anterior, no tipo de questionário 1 foi apresentado um simples demonstrativo com situação atual e futura da empresa após a realização do investimento, no questionário tipo 2 essas informações foram transmitidas em forma de texto, evidenciando através de porcentagens as alterações na receita, custo, despesa e assim no lucro.

Gráfico 3: Demonstrativos contábeis (situação atual e futura) X texto informativo 


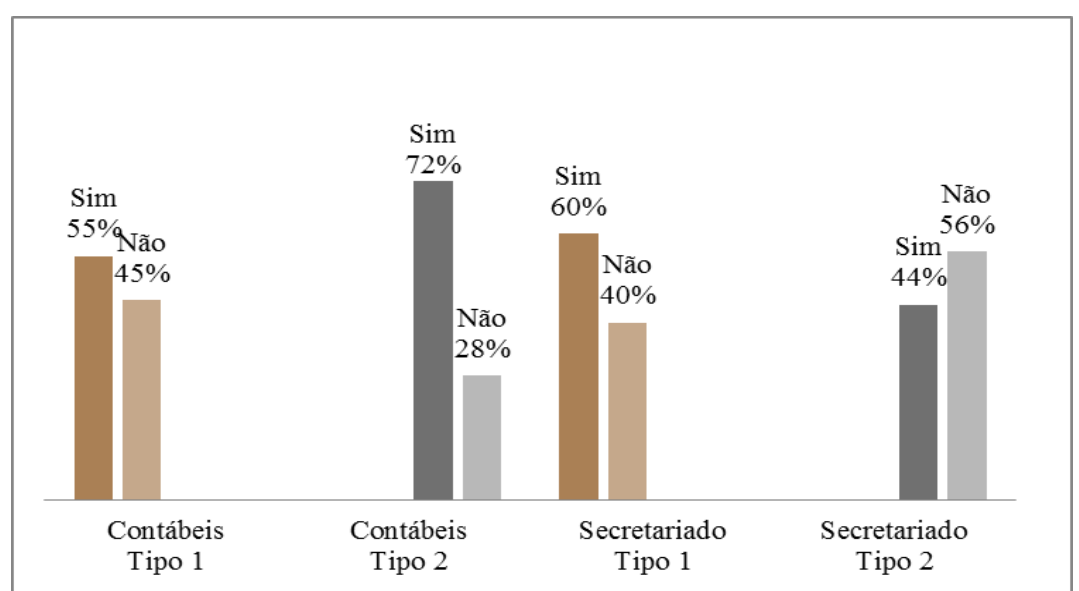

Fonte: Produção do Próprio Autor.

Como resultado disso tem-se que para os alunos de Ciências Contábeis, o efeito novamente não se confirmou e para os alunos de Secretariado ocorreu o inverso. A não confirmação do efeito framing com os estudantes de Ciências Contábeis pode ter se dado pelo constante contato e análise dos demonstrativos contábeis, facilitando assim seu entendimento e não sendo afetado pelo fato de informações serem evidenciadas de forma percentual, pois esses estudantes possuem em sua grade curricular uma disciplina específica para análises de demonstrativos, o que pode explicar essa diferença entre os alunos de Ciências Contábeis e Secretariado Executivo Bilíngue.

O oitavo problema do questionário trazia demonstrativos contábeis de duas empresas, onde uma apresentava notas explicativas e outra preferiu não divulgá-las, com objetivo semelhante ao quinto problema, que era saber se os estudantes optariam em investir seu capital apenas em empresas com lucros elevados, associado ou não a um bom nível de informação, essa situação diferencia-se da citada por trazer demonstrativos ligados a notas explicativas. No questionário tipo 1 a empresa FTY é aquela com maior lucro e com divulgação de notas explicativas e a empresa XYZ é a que tem menor lucro e sem divulgação de notas explicativas, já no questionário tipo 2 a empresa FTY é aquela com menor lucro, mas com divulgação de notas explicativas e a empresa XYZ é a que tem maior lucro, mas sem divulgação de notas explicativas. $\mathrm{O}$ resultado disso é apresentado no gráfico 4.

Gráfico 4: Demonstrativos contábeis associados a notas explicativas X demonstrativos contábeis 


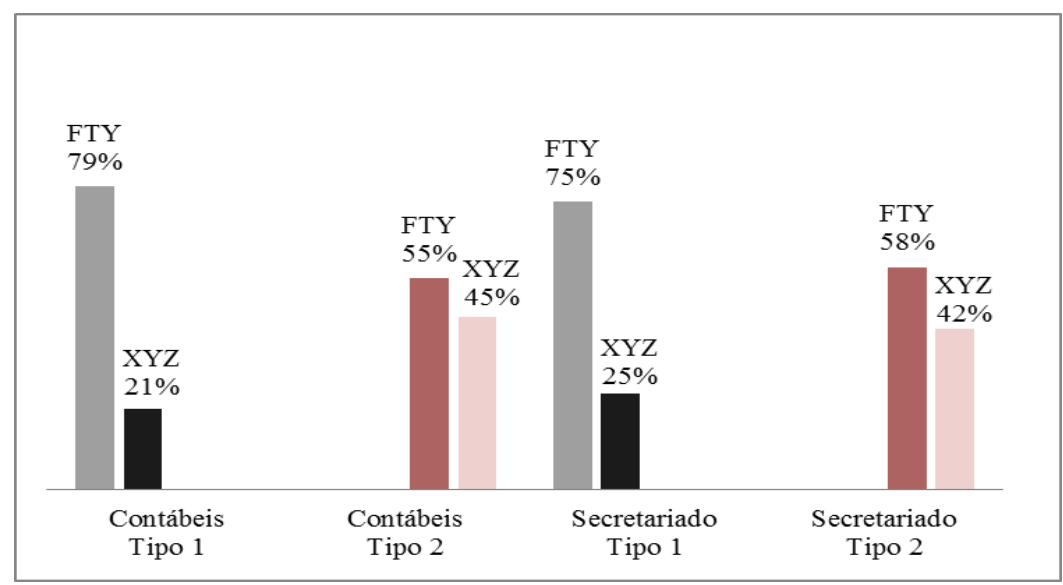

Fonte: Produção do Próprio Autor.

Os alunos de Ciências Contábeis tiveram comportamento igual ao obtido no quinto problema, não sendo afetados pelo efeito almejado nessa situação. Eles novamente tomaram suas decisões embasadas no nível de informação apresentado pela empresa, associadas ou não pelo maior lucro. Semelhantes aos alunos de Contabilidade, os de Secretariado se comportaram da mesma forma, optando por investir seu capital na empresa com maior divulgação de informações, esse resultado contraria o obtido no quinto problema em que os mesmos optaram por realizar seu investimento na empresa com maior lucro, isso pode ter ocorrido devido a presença de demonstrativos contábeis associados a notas explicativas que traz a luz informações adicionais difíceis de serem obtidas por usuários externos, o que fez com que eles tirassem o foco do lucro, fixando assim sua atenção também em informações que seriam provavelmente impossíveis de retirar dos demonstrativos contábeis.

No nono problema almejou-se saber se alterando a escala de um gráfico que evidencia o lucro de diversos anos de uma empresa, causaria mudança na tomada de decisão dos indivíduos. Nessa situação evidenciou-se a evolução do lucro de duas empresas no período de 5 anos e a mudança na escala gráfica de uma das empresas buscou conhecer se isso daria uma impressão de menor queda (impressão positiva) na empresa em que as escalas foi maior. Para confecção do gráfico foi utilizado os mesmos dados, ou seja, os valores atribuídos para o lucro anual eram iguais para as duas empresas, o que mudou foram as escalas do gráfico que evidenciou a situação. No questionário tipo 1, a empresa Beta evidenciou seu lucro com o gráfico na escala normal e a empresa Alfa foi aquela em que a escala foi alterada para mais, a fim de causar o impacto positivo; no questionário tipo 2, ocorre o contrário. 


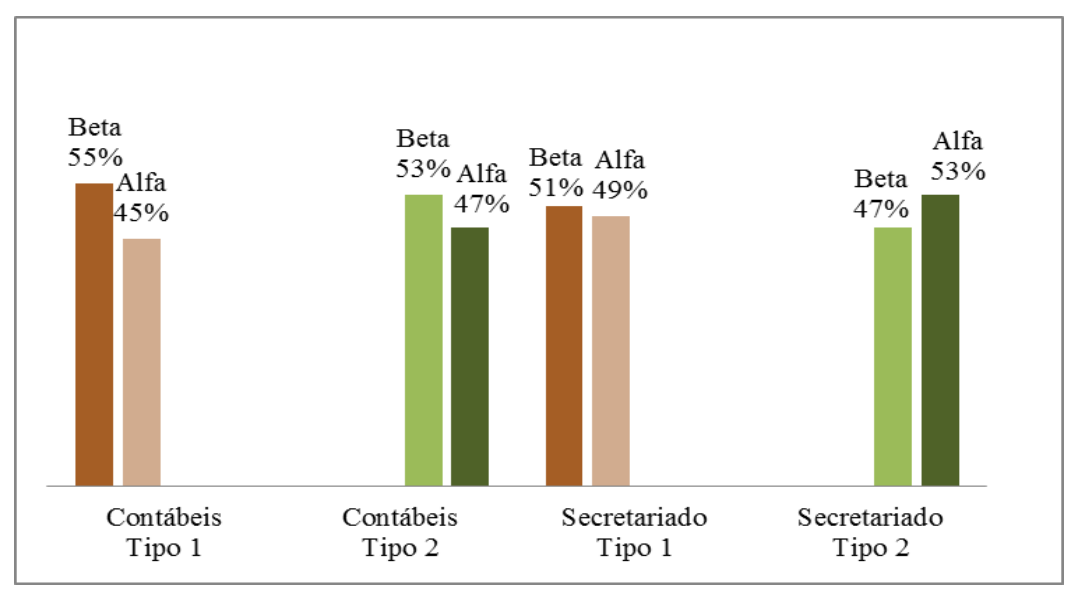

Fonte: Produção do Próprio Autor.

Analisando o gráfico observa-se que a mudança na escala de um dos gráficos não causou impacto sobre a amostra, sendo assim o resultado esperado com a manipulação não foi alcançado. Os estudantes de Ciências Contábeis escolheram investir seu capital na empresa Beta nos dois tipos de questionários, sendo que no questionário do tipo 1 essa empresa possuía sua representação gráfica em escalas normais e no questionário do tipo 2 sua representação gráfica em escalas alteradas. Os discentes de Secretariado Executivo Bilíngue também não foram afetados pela manipulação, a maioria deles escolheram no questionário do tipo 1 e do tipo 2 a empresa que possuía sua representação gráfica em escalas normais. Comparando este estudo com o estudo de Silva e Lima (2007), obteve-se, para essa situação, resultados distintos. No trabalho citado, o autor buscou o mesmo objetivo aqui buscado, sendo que em seu estudo a alteração gráfica exerceu uma forte influência na percepção dos alunos e os mesmos optaram pela empresa que estava representada pelo gráfico com alteração na escala.

Como resultado geral os alunos de Ciências Contábeis mostraram-se avessos ao risco, o que pode ter influenciado para o não impacto causado pelo efeito framing. Acredita-se que o conservadorismo impactou de forma positiva para que essa amostra não alterasse sua decisão quando expostos a situações com formulação diferenciada, devido a prudência de se analisar cuidadosamente as opções. $\mathrm{O}$ contrário pode ser justificativa para os resultados obtidos com os alunos de Secretariado Executivo Bilíngue que sofreram impactos em sua tomada de decisão confirmando o efeito framing e mostraram-se avessos ao risco nos prospectos positivos (ganhos) e propensos ao risco nas opções de investimentos que abordaram prospectos negativos (perdas).

\section{CONSIDERAÇÕES FINAIS}

Diante das evidências de que os aspectos psicológicos influenciam de forma significativa o processo decisório, este trabalho teve como objetivo principal identificar os impactos do efeito framing nas decisões de investimento dos estudantes dos cursos de Ciências Contábeis e Secretariado Executivo Bilíngue da UFPB Litoral 
Norte - Mamanguape, observando mudanças na escolha dos mesmos quando situações são expostas no prospecto de ganhos ou perdas e com modificações em sua estrutura.

Como resultado desse estudo tem-se que os estudantes de Ciências Contábeis possuem um comportamento conservador em todas as situações (ganhos ou perdas), e os mesmos não mudaram suas decisões quando expostos a situações com modificações em sua estrutura (framing).

Já para os alunos do curso de Secretariado Executivo Bilíngue, os resultados foram distintos em relação aos alunos de Ciências Contábeis, pois eles mostraram-se avessos ao risco em situações de ganhos e propensos quando em situações de perdas, associado a alteração na escolha quando expostos a situações com formulação diferenciada, confirmando o efeito framing. Somando assim como o estudo de Galeno et al (2009), Haubert, Lima e Herling (2012) e Kahneman e Tversky (1979).

Com o observado nesse estudo pode-se inferir que o nível de conhecimento específico influencia positivamente para o não impacto da formulação diferenciada na tomada de decisão em situações arriscadas. Assim como o nível de conservadorismo, que faz com que haja um maior grau de verificabilidade dos acontecimentos antes da tomada de decisão.

Esse trabalho vem contribuir com o enriquecimento das finanças comportamentais e sua teoria no Brasil e sugere-se para pesquisas futuras a replicação do estudo com os demais cursos da UFPB - Litoral Norte, abordando docentes e discentes. Outra vertente seria estender o estudo a outros vieses comportamentais, o que fará conhecer de forma mais detalhada o perfil desses em suas tomadas de decisão, além de ser válido associar a correlação do perfil dos respondentes com as respostas do efeito framing, assim como as respostas do efeito framing com o viés de aversão a perda e a outros vieses comportamentais. E outro ponto relevante para análise deste tipo de pesquisa será a inclusão de testes estatísticos para aumentar a robustez dos resultados.

\section{REFERÊNCIAS}

BASU, S. The conservatism principle and the asymmetric timeliness of earnings. Journal of Accounting and Economics, v. 24, p. 3-37, 1997.

CARMO, L. C. Finanças Comportamentais: uma análise das diferenças de comportamento entre investidores institucionais e individuais. 2005. 91 f. Dissertação (Mestrado em Administração). Pontifícia Católica do Rio de Janeiro - PUC-RJ, Rio de Janeiro, 2005.

GALENO, M. M. et al. Vieses comportamentais presentes na tomada de decisão de investimentos: um estudo empírico realizado em pós-graduação. In: Anais... VI Simpósio de Excelência em Gestão e Tecnologia - SEGeT, Rio de Janeiro, p. 1-17, 2009. 
HAUBERT, F. L. C.; LIMA, M. V. A.; HERLING, L. H. D. Finanças comportamentais: um estudo com base na teoria do prospecto e no perfil do investidor de estudantes de cursos stricto sensu da grande Florianópolis. Revista Eletrônica Estratégia e Negócios, Florianópolis, v. 5, n. 2, p. 171-199, mai-ago/2012.

FAMA, E. Efficient Capital Markets: A Review of Theory and Empirical Work. Journal of Finance, v. 25, n. 2, p. 383-417, mai/1970.

FERREIRA JR, G. Contador conservador ou ser humano conservador? Um estudo sob a perspectiva da contabilidade comportamental. 2012. 181 f. Dissertação (Mestrado em Ciências Contábeis) - Universidade Federal da Bahia, Salvador, 2012.

KAHNEMAN, D.; TVERSKY, A. Prospect theory: an analysis of decision under risk. Econometrica, v. 47, n. 2, p. 263-29, mar/1979.

$\therefore$. Choices, Values, and Frames. American Psychologist, v. 39, n. 4, p. 341$350, \mathrm{abr} / 1984$.

KIMURA, H. Aspectos comportamentais associados às reações do mercado de capitais. Revista de Administração de Empresas Eletrônica, São Paulo, v. 2, n.1, p. 1-14, jan-jun/2003.

LIMA, D. H. S. Análise do impacto da divulgação adicional de informações contábeis com o uso de recursos textuais elou gráficos sobre a percepção dos indivíduos quanto ao nível de disclosure de uma entidade. 2012. 118 f. Tese (Doutorado em Ciências Contábeis) Programa Multiinstitucional e Inter-Regional de Pós-Graduação em Ciências Contábeis da Universidade de Brasília, Universidade Federal da Paraíba, Universidade Federal de Pernambuco e Universidade Federal do Rio Grande do Norte, Natal - RN. 2012.

LIMA, M. V. Um estudo sobre finanças comportamentais. RAE-eletrônica, São Paulo, v. 2, n. 1, p. 1-19, jan-jun/2003.

MAYER, V. F.; AVILA, M. G. A influência da estruturação da mensagem em comportamentos relacionados à saúde: um teste experimental. Saúde Soc., São Paulo, v. 19, n. 3, p. 685-697, jul-set/2010.

MILANEZ, D. Y. Finanças comportamentais no Brasil. 2003. 53 f. Dissertação (Mestrado em Economia) - Faculdade de Economia, Administração e Contabilidade, Universidade de São Paulo, 2003. 
SILVA, C. A. T; LIMA, D. H. S. Formulation Effect: Influência da Forma de Apresentação sobre o Processo Decisório de Usuários de Informações Financeiras. In: Anais... XXXI Encontro da ANPAD, 2007. Rio de Janeiro, 2007.

TOMASELLI, T. R. A ACP e a tomada de decisão em investimentos. Fractal: Revista de Psicologia, v. 22, n. 3, p. 525-542, Rio de Janeiro, set-dez/2010.

TORRALVO, C. F. Finanças comportamentais: uma aplicação da teoria do prospecto em alunos brasileiros de pós-graduação. 2010. 129 f. Dissertação (Mestrado em Administração) - Universidade de São Paulo. São Paulo, 2010.

TVERSKY, A.; KAHNEMAN, D. Judgment under uncertainty: Heuristics and biases. Science, New Series, v. 185, n. 4157, p. 1124-1131, set/1974.

$\therefore \quad$. Rational choices and the framing of decisions. The Journal of Business. Chicago, v. 59, n. 4, p. 251-278, Out. 1986.

YAZBEK, P. Investidor pessoa física na Bolsa bate recorde em maio. 2013. Texto Online. Disponível em: <http://exame.abril.com.br/seu-dinheiro/noticias/investidor-pessoafisica-na-bolsa-bate-recorde-em-maio>. Acesso em: 08 mar. 2014. 